\title{
What Information Are We Providing to Users with Disabilities? An Analysis of ARL Libraries' Accessibility Webpages
}

\section{Amelia Brunskill, Catherine Lantz, and Kavita Mundle}

\begin{abstract}
An analysis of ARL libraries' webpages of accessibility information revealed wide variation in terms of these pages' findability, length, and coverage. Overall, most of the content elements that were searched for, based on previous webpage studies and user-centered research, were not present on the majority of the webpages. There is clearly much room to expand the accessibility information most ARL libraries provide, which raises questions about whether this is primarily an issue of documentation or reflects true gaps in available resources, services, and facilities. A guide for auditing these webpages was developed to help libraries assess potential gaps in these webpages.
\end{abstract}

\section{Introduction}

Library websites are the primary mechanism for the dissemination of ARL libraries' accessibility information, ${ }^{1}$ and most ARL libraries have dedicated pages of information specifically for this purpose. $^{2}$ These pages, which will be referred to as "accessibility webpages," can document information on library resources, services, and facilities that could be relevant to a wide array of users with disabilities.

Unfortunately, while libraries' accessibility webpages have the potential to be highly useful to both users with disabilities and those assisting them, past studies of academic library accessibility pages have found common deficits among these pages in terms of both their findability and their content. ${ }^{3}$ These previous studies also do not appear to have involved any consultation with users with disabilities, which prompted Amelia Brunskill, one of this study's authors, to conduct a series of interviews with university students with disabilities to learn more about their needs and preferences for these pages. ${ }^{4}$ The participants' responses provided an expanded view into what information accessibility pages could contain to more fully support students with disabilities, including those with invisible disabilities, such as attention deficit hyperactivity disorder (ADHD) and depression, which are some of the more prevalent disabilities within the university student population. ${ }^{5}$

Armed with insights from that study, and a hope that ARL libraries may have expanded their accessibility webpages in recent years, this study located and analyzed ARL libraries'

\footnotetext{
*Amelia Brunskill is Information Services and Liaison Librarian, Catherine Lantz is Reference and Liaison Librarian, and Kavita Mundle is Electronic Resources Librarian, all at the University of Illinois Chicago; email: abrunsk2@uic.edu, clantz@uic.edu, kavita@uic.edu.@2021 Amelia Brunskill, Catherine Lant, and Kavita Mundle, Attribution-NonCommercial (https://creativecommons.org/licenses/by-nc/4.0/) CC BY-NC.
} 
accessibility webpages, examining them for specific elements of interest that emerged in previous studies pertaining to the accessibility pages' location, language, structure, and content.

\section{Background}

Discussions around accessibility in libraries have often focused on issues pertaining to legal compliance. As such, it is important to note that, while both the American Disabilities Act $(\mathrm{ADA})^{6}$ and the Rehabilitation Act of $1973^{7}$ focus on users with disabilities and have compliance implications for libraries, neither stipulate what, if any, documentation on compliance efforts should be provided to library users. Similarly, while the Web Content Accessibility Guidelines (WCAG) ${ }^{8}$ address how to make web content accessible to people with disabilities, they do not provide guidance on what informational content should be provided to assist these users. In summary, a library could have a physical building, resources, and services that address ADA and Rehabilitation Act concerns without providing relevant accessibility information on their website, and a library's accessibility webpage could meet WCAG guidelines without providing any usable information about a library to a user with disabilities. Therefore, assessment of a library's accessibility page should not be primarily viewed in terms of legal compliance, but in terms of the degree to which it allows users with disabilities to learn about a library's resources and services and to understand what supports or barriers they would encounter within the physical library environment.

Part of the potential great value of an accessibility webpage is the opportunity it presents for a library to connect with users with disabilities without requiring these users to provide any information on their disability status. This is important since many university students with disabilities often do not wish to disclose their disabilities to others unless strictly necessary, ${ }^{9}$ and they may either never register with their campus disability office or delay doing so until prompted to by an academic crisis. ${ }^{10}$

The absence of relevant documentation about library policies pertaining to users with disabilities can actually cause students to feel guilty about asking for needed help and concerned that such requests might be met with hostility. ${ }^{11}$ Information omitted from the library's webpage may, unfortunately, prove difficult to obtain via other means, as JJ Pionke (2017) noted: "patrons felt that there were many times when they asked for help but that they didn't get it, it was too hard to get help, or the library employee wasn't patient enough." ${ }^{12}$

While the primary intended audience for accessibility pages should be users with disabilities, an accessibility page can also serve as a tool for library workers assisting these users. Library workers may benefit significantly from additional guidance in this area; in site visits to eight academic libraries, Sue Samson (2011) found only 37.5 percent of the libraries determined that their library staff had all the information they needed to serve individuals with disabilities. ${ }^{13}$ Two more recent studies continued to find gaps in librarian and library staff knowledge in this area: Joanne Oud (2019) found that librarians with disabilities reported a lack of awareness about disability issues among their colleagues, ${ }^{14}$ and JJ Pionke (2020) noted that many library workers responded to accessibility questions with "frustration and fear" and that almost 70 percent of librarians interviewed were very interested in more training in this area. ${ }^{15}$ Naturally, accessibility webpages should supplement rather than substitute for additional training, but they can serve as a helpful refresher on existing policies, procedure, and options, as well as a reference for information about the physical building. 
In 2018, ARL member libraries were surveyed about their support of people with disabilities and the responses from 67 institutions, 54 percent of those surveyed, were published in SPEC kit 358: Accessibility and Universal Design. ${ }^{16}$ All respondents indicated that at least one of their service desks, classrooms, restrooms, and drinking fountains were accessible to users with disabilities, and the majority indicated their library staff would provide assistance to users with disabilities with a wide variety of tasks and that their libraries had accessible/ height-adjustable workstations, assistive technology, scanners with OCR capabilities, speakers, microphones, and magnifiers or CTVs. While online documentation of this information was not asked about in the survey, 94 percent of the respondents indicated the library website was a primary way of publicizing accessibility information, and the SPEC kit also highlighted select accessibility webpages.

Clearly, accessibility webpages have the potential to serve an important role in providing information that both users with disabilities and library staff can benefit from in a centralized location that can be privately accessed and consulted without requiring disclosure. ARL libraries also have a considerable amount of information about their accessibility offerings that could potentially be provided on these pages. Reviewing the current documentation on ARL libraries' accessibility webpages can provide insights into whether libraries' existing accessibility webpages are likely supporting or disappointing the users who locate them.

\section{Literature Review}

The earliest study located that investigated academic libraries' accessibility pages was conducted by Rebecca Power and Chris LeBeau (2009). ${ }^{17}$ This study, which referred to these pages as disability services pages, focused on the needs of users with visual disabilities and indicated that the five essential components of these pages were contacts, services, building access, assistive technology, and database accessibility. Mary Cassner, Charlene Maxey-Harris, and Toni Anaya (2011) reviewed ARL library accessibility webpages, discussing the located content of these pages under the headings of general features, services, staffing, facilities, and assistive technology. ${ }^{18}$ Stephanie Graves and Elizabeth German (2018) had a more narrow focus than the prior two studies, looking solely at whether these pages provided information on library instruction content, including the physical and technical accessibility of library classrooms. ${ }^{19}$ K.T.L. Vaughan and Stefanie Warlick (2020) went broader again, reviewing accessibility webpages for the presences of 12 specific content types: statement, campus contact, library contact, AT lab, book/article retrieval, building information, computers and equipment, research help, study rooms, circulation help, resource inks, and video captioning. ${ }^{20}$

All four studies found that the presence of information within the defined categories was limited. While more than half the pages found by Cassner et al. included information on communication, retrieving materials, parking, structural modifications, and reference help, fewer than half included information about elevators, restrooms, branch library accessibility, proxy borrowing, or emergency procedures. Power and LeBeau found that some accessibility pages contained as little as a single sentence, and while most pages they studied mentioned assistive technology, they did not always specify what software or hardware was available, and many libraries did not include information about bathrooms, fountains, stacks, classrooms, or study areas. Roughly a decade later, Graves and German found that few accessibility pages mentioned library instructions programs and services, and Vaughan and Warlick found fewer than half of the pages studied included information on seven of their 12 content 
types of interest: information on the building, computers and equipment, research help, study rooms, circulation help, resources links or video captioning. Vaughan and Warlick also found, unlike the other three studies, that the majority of the webpages they reviewed, which were 40 four-year academic libraries in Virginia, did not contain an accessibility webpage at all. ${ }^{21}$

As discussed previously, there was no indication that these studies involved consultation with users with disabilities themselves; unfortunately, there is often a lack of involvement of users with disabilities in library studies pertaining to accessibility. ${ }^{22}$ However, some library studies have consulted with these users more broadly on library experiences, and some issues and priorities include inaccessibility of facilities within libraries and technology issues, ${ }^{23}$ empowerment, communication, signage, privacy, and marketing, ${ }^{24}$ and a desire for online environments to be inclusive that allow them to make informed, personalized choices. ${ }^{25}$ Usability studies of library webpages with users with visual impairments have also found that there can be a steep learning curve to using library websites and considerable barriers that can lead to some students being unable to successfully navigate the site. ${ }^{26}$ It is also worth noting that, while the technical accessibility of library websites has been frequently studied, sometimes involving users with vision and print disabilities, accessibility errors continue to be commonly found. ${ }^{27}$ This further increases the need for an accessibility webpage to provide useful information in one location rather than navigating throughout the site to search for different pieces of needed information.

When Brunskill (2020) interviewed 12 students with disabilities about their needs and preferences for libraries' accessibility webpages, many participants were not confident such a page would even exist. ${ }^{28}$ When presented with four potential dropdown menu options under which accessibility webpages were commonly located in a small sample of ARL libraries' homepages, the one most commonly selected first was "Services" but multiple participants expressed uncertainty and mentioned that the link should instead be a top-level item. In terms of the desired content elements for an accessibility webpage, a number of the participants discussed information about the interior and exterior environment of the library they'd need to assess whether they will be able to successfully get to and navigate within the library to find needed materials and an appropriate place to study. Participants also brought up content elements rarely or never reviewed in previous accessibility webpage studies, such as maps, quiet spaces, lighting, and details about the furniture other than the adjustability of tables. Several participants also described the potential importance of services like shelf pulling and proxy borrowing, but often in the context of assuming such services would not actually be available.

Interestingly, floor maps were one of the most commonly mentioned important library website elements in a 2019 survey of university students, ${ }^{29}$ and Rachel M. McMullin and Kerry R. Walton (2019) discuss how students with ASD can find navigating the physical space of a library overwhelming and so early communication with them about available library spaces is important to ensure they don't end up avoiding the library entirely. ${ }^{30}$ When Jaci Wilkinson and Kyle Breneman (2020) reviewed and analyzed the floor plans posted on 37 academic library websites, they found floor plans were included by all but one of these institutions. ${ }^{31}$ However, while all floor plans included information about book stacks and restrooms, information on building entrances and parking was not consistently present, the majority did not include accurate representation of furniture or seating options, and none included information about natural lighting. 
Overall, the literature indicates that it would be useful to revisit ARL libraries' accessibility webpages to see what information they are providing to users with disabilities, informed by feedback from these users.

\section{Methods}

\section{Definition of an Accessibility Webpage}

Accessibility webpages were defined as a page on the library website that focused specifically on information for users with disabilities addressing the library's resources, services, and/or facilities. For the purpose of this study, LibGuides were also included if a library used them instead of a webpage located within the larger university web architecture. For webpages with multiple tabs or subpages, all pages within it were included for analysis. Links within the page were also followed if they went to a subpage within the architecture of the page, or to a page that a reviewer determined that, while not technically falling under the same URL path, was still for content that was specifically oriented toward users with disabilities and was part of the same library domain. With the exception of maps, links to webpages outside the library were not followed.

\section{Process for Identifying Accessibility Webpages}

The authors reviewed the list of all ARL member libraries ${ }^{32}$ and initially excluded only those libraries not associated with academic institutions, such as the Library of Congress and the Smithsonian Library. One additional library was ultimately excluded after it was found that its entire webpage was in French, leaving 115 ARL libraries as the subjects for this study. For these 115 libraries, two of the authors used the homepage link provided on the ARL member list as a starting point and searched each website for an accessibility webpage. Since dynamic web elements such as dropdown menus can create accessibility barriers for people who rely on keyboards or screen readers, ${ }^{33}$ and make content less prominent even for sighted users, the authors started by looking for a top-level link, one that was immediately visible and not concealed within a dropdown menu, from the homepage to the accessibility page. If the researchers did not locate a link through first a visual scan and then a page search using control $+f$ for "accessibility" and then "disab" to locate terms such as disabilities and disabled, any dropdown menus were reviewed. If no links were found within the dropdown menus, the researchers then used the library webpage's search function for "accessibility" and then "disability."

For each library, information was captured about the homepage URL, the name of the page as listed on the homepage, whether there was a direct link from the homepage, if applicable the name of the dropdown menu item it was located under, and the name and URL of the accessibility page.

\section{Survey Instrument}

A survey instrument was developed in Qualtrics for the three authors to identify relevant information from the located accessibility webpages. The broad categories and specific items for documentation were informed by the existing literature on both accessibility webpages and the library needs and preferences of users with disabilities. The instrument prompted authors to document specific information about the structure of the webpage, the presence of a welcoming/introductory statement, contact information, and the presence or absence of information within the following potential content areas: technology and specialized equip- 
ment, facilities within the building, exterior facilities, maps, services, collections, and links to external resources. Response options for most items were yes, no, or unsure and also allowed for any relevant text from the webpage to be copied and pasted into the survey. An option was also included toward the end of the survey to allow authors to note attributes of the webpage that they found interesting or otherwise noteworthy but that were not specifically addressed elsewhere in the survey.

There were two rounds of testing of a random sample of identified webpages to assess the survey instrument and identify any clarifications that might need to be made to facilitate consistency among coding and to uncover any potential grey areas in terms of website structure or language. After these two rounds, in which all reviewers reviewed the selected webpages, the survey was finalized, all previous coding was deleted, and the webpages were divided among the three authors.

During the data analysis portion, the results were again divided, this time by content area. Each reviewer reviewed the data for their assigned section, evaluating the associated text for items labeled as "unclear." It was up to the individual reviewer to confirm the status as unclear or to instead mark them as "yes" or "no" responses instead. Some items were brought to the full group for discussion for a final decision.

\section{Word Count Data}

Gathering word count information was delegated to one author. The word count for each identified accessibility webpage was found by copying and pasting the relevant text into a word document that was saved into a central folder. Word count was gathered to provide an imperfect but often revealing view into how much space and content was dedicated to accessibility information.

\section{Findings}

\section{Page Existence and Prominence} within the Library Webpage

The authors located accessibility webpages for 93 percent (107) of the 115 libraries identified as ARL libraries for academic institutions. Among the libraries with an accessibility webpage, the majority of the links were either concealed within a dropdown menu or not included on the homepage at all (see figure 1 for breakdown).

For those links found underneath a dropdown menu, the most common menu option they were found under was "Services," with 16 using that exact heading and five additional libraries using a heading that included that term, such as "My Services" or "Services and Help."

In terms of the language used for the link text itself, 28 libraries used the term "accessibil-

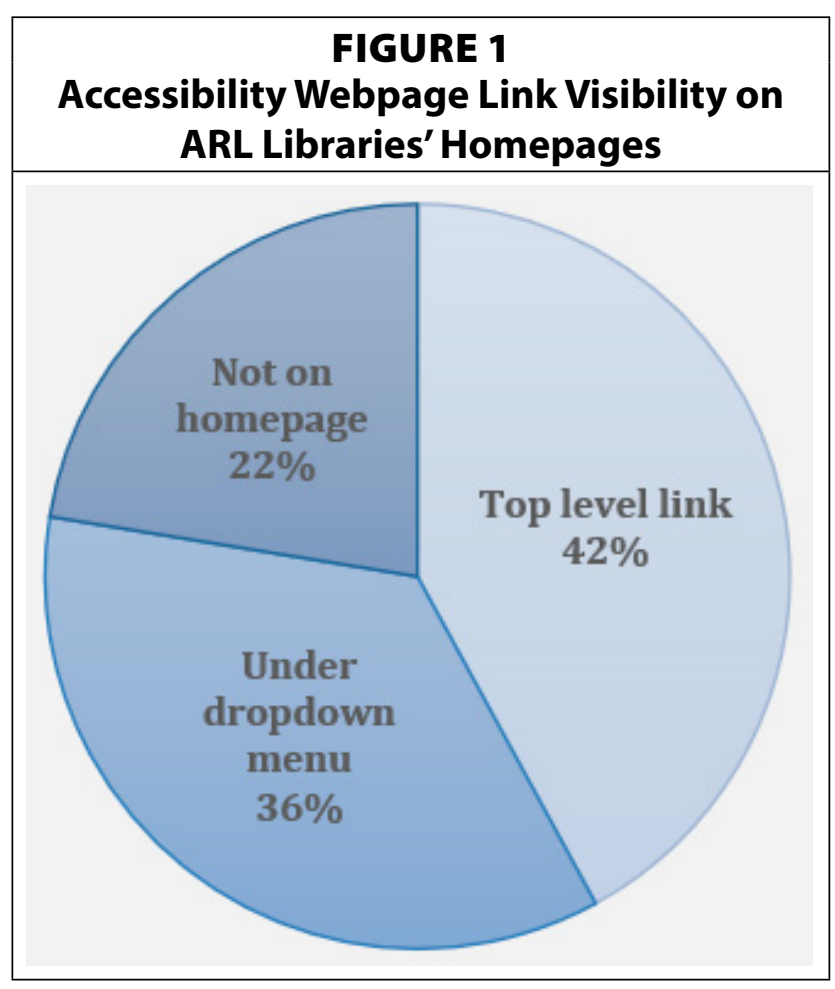


ity" within the link text, 14 used "disability," and 22 used "disabilities." For 22 libraries, the link to the accessibility webpage was simply "Accessibility," "Accessibility Services" was used for 13 libraries, and nine libraries used "Patrons/Persons with Disabilities." It is worth noting that the authors also encountered some "accessibility" links on library webpages that instead linked to universitywide messaging about accessibility. Sometimes this link was part of a static university footer, but there were also instances when it was mixed in with library-specific links.

\section{Length and Structure}

The accessibility webpages varied enormously in their length, ranging from a mere 48 words to 6,307 words. The average number of words was 959, and there were a handful of large outliers. The distribution is shown in figure 2.

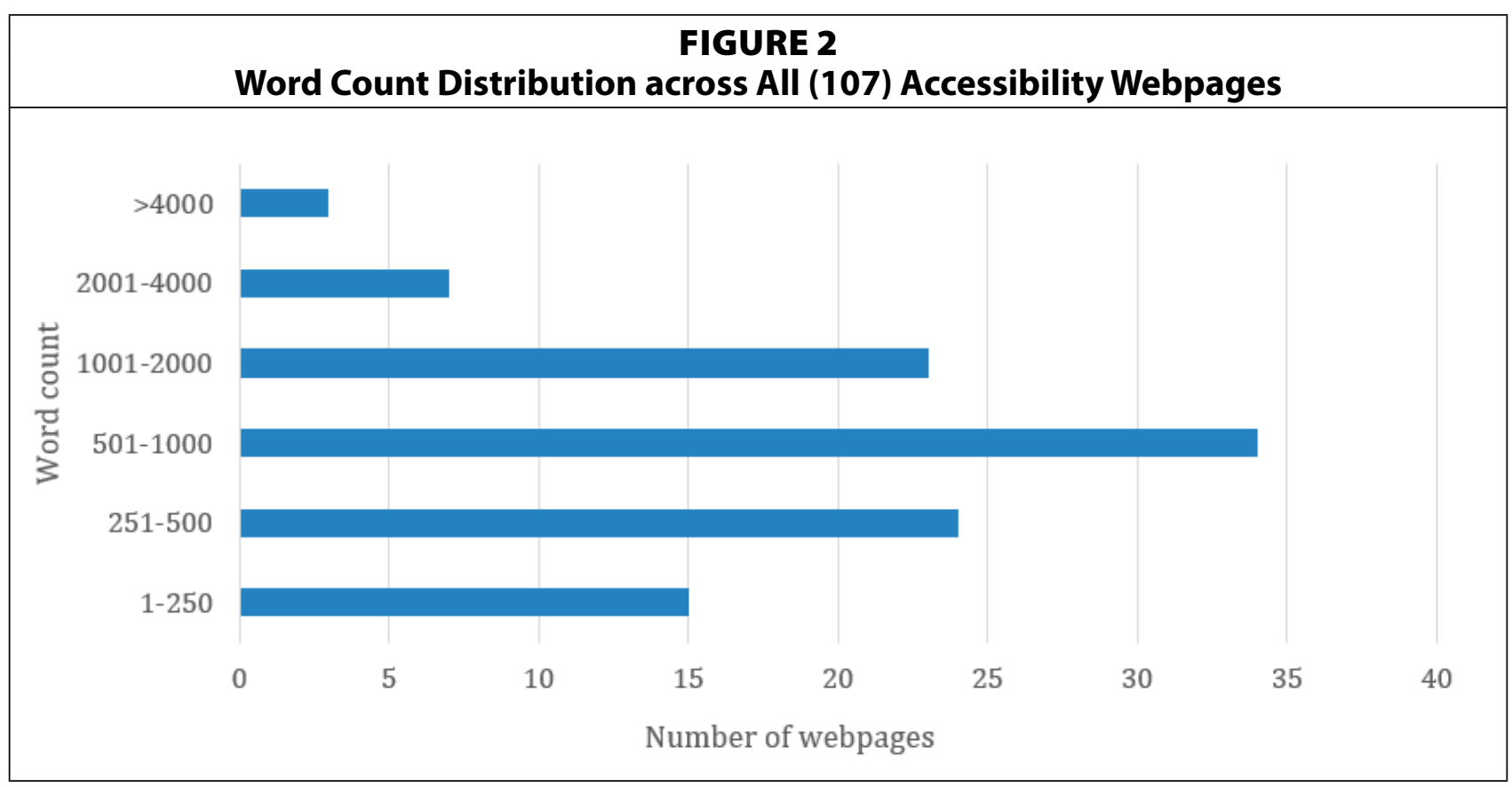

In terms of structure, the majority of the pages $(68 \%, 73)$, consisted of a single page without tabs, while 25 percent (27) of the pages consisted of multiple pages or tabs. Seven pages were marked as unclear by the reviewer as the structure did not clearly fall into either a single page or multiple page construction.

\section{Content}

Overall, most webpages did not contain the majority of the content elements of interest. The five content elements that were included by the majority of the webpages were introductory language, information on entrances, information on book retrieval, a list of accessibility software, and a link to an external campus resource-typically the campus disability services office. The remaining elements were found in fewer than half of the pages, and fewer than 15 percent included information on quiet spaces, distraction-free spaces, lighting, ways to contact the library other than via email or phone, public/campus transportation options, service animals or emotional support animals, library instruction, or accommodations pertaining to interlibrary loan. Specific content elements are explored in further detail below. 


\section{Introductory Language}

The majority $(77.6 \%, 83)$ of pages included some kind of introductory language to explain the purpose of the page, but 16 percent (17) consisted only of welcoming language or a mission statement, with no additional content.

\section{Contact Information}

The vast majority of webpages did not include information on alternate methods of communication with the library beyond an email address or phone number. A few webpages included information on sign language interpreter options or options for users with hearing loss, such as a TTY (Text Telephone) option. Generic contact information, such as a link to an "Ask a librarian" service, or contacts for specific services were often provided. When a single communication point was offered, the most common option was to a named individual at the library. For six webpages, no contact information was located at all.

\section{Language Indicating Limitations of Services to Specific Disabilities}

While the researchers found that the majority of webpages did not include language limiting services to a particular category of disability, some did contain such language. Often this was due to specific legal requirements, such as references to expanded access to HathiTrust being available for users with print disabilities, and also a reference to Canadian copyright provisions. However, there were also instances of limitations mentioned that were not based on legal constraints, such as only retrieving items from stacks for users who were in wheelchairs or using crutches, or only those with limited vision, or mobility-accessible formats being for users with visual and/or audio impairments, or a space being available for users with visual impairments or a learning disability. Some sites also separated out services by type of disability, and there were also cases where it was unclear if a category of disability was mentioned simply to be illustrative or if the service was limited to users with that category of disability.

\section{Facilities}

Overall, there was a notable lack of information about features of both interior and exterior facilities (see figure 3 for breakdown). Even the two most commonly documented pieces of information about interior facilities, the presence of accessible bathrooms and elevators, were mentioned on fewer than half of the webpages. The third most commonly mentioned item, study rooms, was still mentioned by fewer than a third of the pages. Few webpages discussed quiet space, distraction-free spaces, lighting, accessible furniture other than adjustable tables, service or emotional support animals, or emergency evacuation procedures. For exterior spaces, information on accessible entrances, including descriptions of ramps and automatic doors, was the only feature documented by a majority of the webpages $(53 \%, 57)$.

Among those that did mention quiet spaces, the references ranged from a simple mention that they exist in different areas of the library to specific descriptions of where quiet spaces are located to instructions on how to reserve private quiet areas (study rooms). The libraries that did describe lighting mentioned where it was adjustable, antiglare, natural, or nonfluorescent. A handful of webpages linked to campus and regional transportation services including shuttles, buses and taxis with information, schedules, pickup locations, and accessibility features. One library included a note about how current construction impacted building access. 


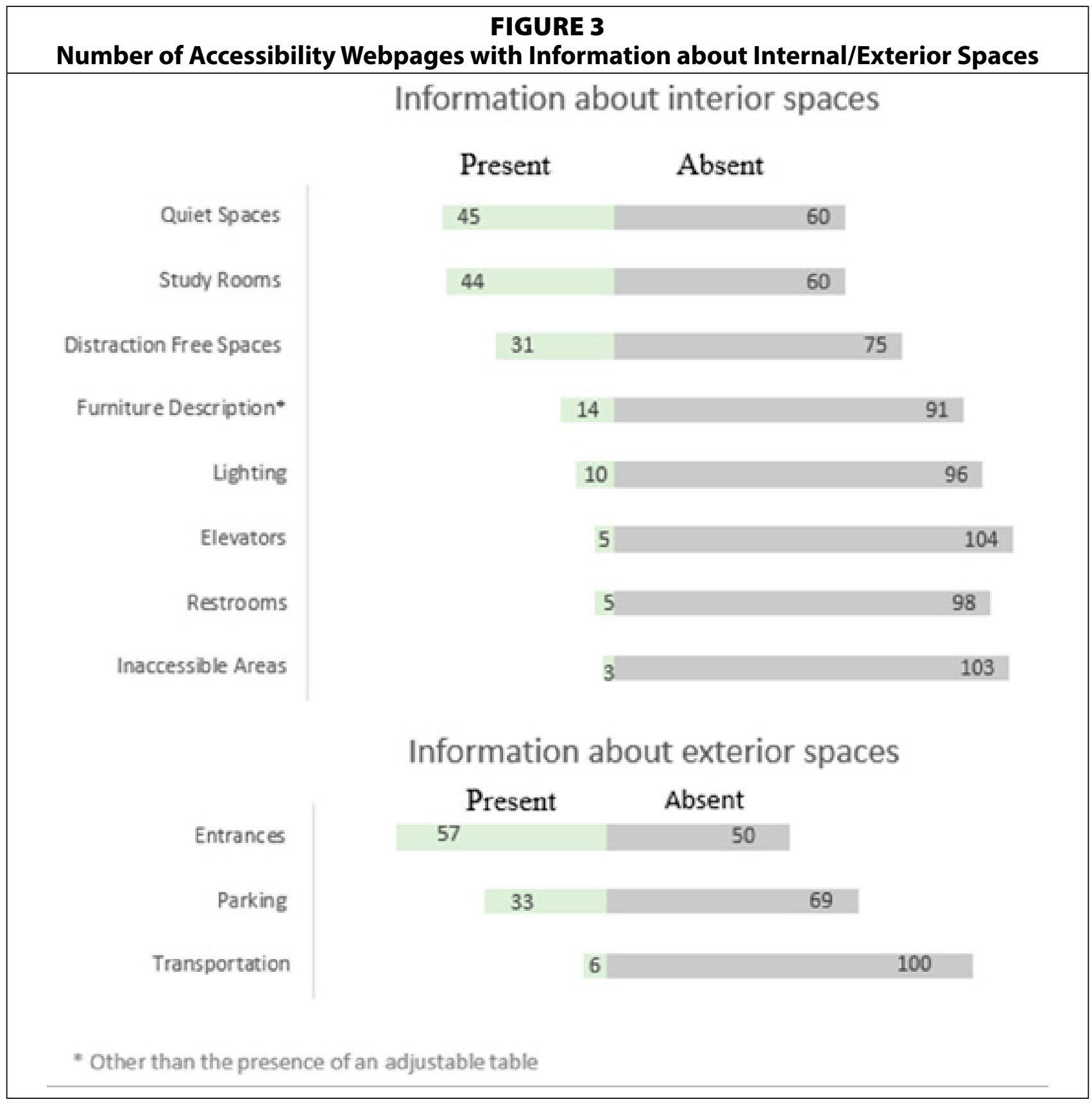

\section{Maps}

Sixty-four percent (68) of webpages did not include any maps, whether directly integrated into the page or a link to a map outside the library website. For webpages that did include maps, the most popular option was to link to campus accessibility maps, followed by direct link to library maps. Only 4 percent (4) of webpages had maps integrated directly into the accessibility page. For the webpages that did include some type of map or map link, the accessibility information most commonly included was the location of an accessible entrance locations, which was found in 13 of the maps.

\section{Research-oriented Services}

Forty-two percent (45) of the webpages referred to research assistance being available, but only a handful of them provided information about help specific to users with disabilities, 
such as booking a consultation in a room with assistive technology/equipment, a reduced distraction environment, or sighted assistance in navigating a webpage. A few pages referenced other assistance library staff could provide, including printing out handouts in large type for patrons with print-related disabilities and arranging for screening of films in which vocal narration/discussion will be required. Several pages referred to personal assistance that was available through campus Disability Services, including readers for materials that could not be made accessible, and volunteers/aids who could provide physical assistance with research work.

Ninety-three percent of the webpages (99) did not list any accommodations for information literacy instruction. Interestingly, while not specifically included as an initial data point, multiple libraries were found to include information on tours and orientations for the library, accommodations for library events, and training on assistive technology.

\section{Collections-oriented Information and Services}

The most commonly mentioned service was book paging/retrieval with 75 percent (80) of the webpages, and some providing specific information about the number of items and/or the timeline for retrieval. Only 30 webpages mentioned proxy borrowing, and only 11 discussed a book delivery option that would send physical items to a patron's home, office, or dorm. Eighty-six of the websites did not include any information on circulation flexibility that could be extended to users with disabilities, such as extended loan periods or circulation of typically noncirculating materials. Among the minority that did, extended loan for reserves materials was the most commonly mentioned option.

With respect to alternate format conversion, no language was found for 46 pages indicating that any such service was available. Additionally, it was sometimes unclear whether the service described on the webpage was distinct from typical document delivery or interlibrary loan services available to all users, and some simply mentioned that help with scanning materials could be provided, while others provided detailed guidance on how to request alternate formats.

Most webpages did not include any information about library materials with accessibility features, such as read-aloud capability or closed captioning. Among those that did, some described book collections for students with print disabilities, materials with closed captions, large print materials, braille materials, Bookshare-an online library of accessible ebooks for people with print disabilities - and one included a LibGuides page on audiobooks. Some libraries included instructions for how to locate materials in a certain format, or with a feature such as closed captions, in the catalog or in the stacks. HathiTrust was mentioned by 28 percent (30) of pages, and some also referred to the Internet Archive Collections for users with Print Disabilities. Some pages described accessibility information by publisher.

\section{Technology: Software and Hardware/Equipment}

Eighty-seven percent (93) of the webpages referenced accessibility software, and 53 percent (57) also provided a list of the software provided. However, few provided information about the specific edition of the software, and some pages referred to software not by name but by general function ("screen reader software," "voice recognition software"). Eight webpages did not include a list, but instead included a link to another university webpage implied to contain this information. 
The four most commonly mentioned software programs were JAWS, Zoom Text, Kurzweil, and Dragon. A list of software programs mentioned by three or more pages is included in appendix A. Software programs mentioned that might have accessibility features, but were not accessibility-specific, such as Microsoft Office and Adobe Acrobat, were omitted.

Compared to software, specifics around hardware and equipment were much less commonly discussed on accessibility webpages. While there was no type of equipment that was mentioned in the majority of the webpages, the following equipment was mentioned on at least ten webpages: scanners, specialized mice, specialized keyboards, magnifiers, CCTV, and headphones. In three instances, headphones were specified as being noise cancelling, while in another three instances they were specified as having an attached microphone. Six pages mentioned braille embossers. For the keyboards, four were specified as being large print, two as Intellikeys brand (which creates programmable alternative keyboards), one was high contrast, and two were specified as large key. Widescreen monitors were mentioned on some pages, and there were general references to wheelchair-accessible stations and viewing carrels that supported closed captions. In appendix B there is a list of less infrequently mentioned items.

Although the authors did not look for information on such items from the outset, multiple libraries addressed loanable accessibility equipment and/laptops loaded with assistive technology, accessible phones, and lockers. Read-aloud spaces, specialized carts, and loanable wheelchairs were also included on some pages.

\section{Other Resources: Campus Resources and External Resources}

Ninety-three percent (100) of the webpages listed one or more campus resources external to the library. However, the majority of the webpages included only a single link to external campus resources, typically to the central campus page for the Disability Office or Accessibility Services. Much less commonly, links were included to adaptive technology centers, human resources office, other employment-related links, parking services, general campus accessibility information, and campus maps.

Only 21 percent (23) of webpages were found to list one or more community resources. From the webpages with community resources listed, there were 35 listings total. While there were few commonalities among pages in terms of what community resources were listed, links to the ADA were found in several pages. Some webpages included links to state-level services or policies, such as Michigan Commission for the Blind Braille and Talking Book Library, Disability Rights California, and Relay Texas, and a few included links to information about disabilities or to organizations working on disability rights and awareness.

\section{Discussion}

The authors originally anticipated that ARL libraries' accessibility webpages would have made substantial gains since the findings of Cassner et al. (2011), with potential information deficits largely found in less examined accessibility areas such as lighting, navigation information, and quiet spaces. While slight gains were made in the percentage of ARL libraries found to have an accessibility webpage, with Cassner et al. finding 88 percent (87/99) had such a page, ${ }^{34}$ and this study finding 93 percent $(107 / 115)$ had a page, most pages demonstrated considerable room for improvement across all of the reviewed categories of content. Items such as elevators, restrooms, proxy borrowing, and emergency procedures that were frequently omitted a 
decade ago ${ }^{35}$ were still absent from most pages, and information pertaining to the top three content priorities by interviewed students with disabilities - sensory information (noise, privacy, lighting), information about library materials with accessibility features, and details about physical building accessibility ${ }^{36}$-also proved to be in short supply.

Overall, users with disabilities at ARL libraries who are trying to assess whether they will be able to successfully navigate the library space and find a suitable place to study, or get assistance other than book retrieval and information about accessibility software, will typically not find the needed information on libraries' accessibility webpages. Indeed, they might not be able to even locate the accessibility page to begin with, given that fewer than half had a link to it from their homepage that was not concealed within a dropdown menu, and almost a quarter did not link to it from their homepage at all.

While the findings of this study clearly indicate shortfalls in online documentation of content on accessibility webpages, which were largely consistent with deficits found by Vaughan and Warlick (2020), ${ }^{37}$ what is less clear is the reason for these shortfalls. In some cases, it is possible that the omitted content indicates a genuine lack of available services or resources. The low documentation of information on proxy borrowing, book delivery, or expanded options for interlibrary loan may unfortunately indicate that many ARL libraries do not formally offer these services, which were not specifically inquired about in the 2018 Accessibility and Universal Design survey. ${ }^{38}$ It is likewise possible, although somewhat surprising, that accessibility-oriented hardware and equipment may not be part of most institutions' holdings. While scanners with OCR capabilities, speakers, microphones, and magnifiers or CTVs were indicated to be owned by more than half of the responding ARL libraries in the SPEC kit, it may be the case that the responding libraries tended to be ones that were further along with their accessibility efforts and that the availability of these items in the ARL libraries that did not respond was significantly lower.

In other cases, it seems highly probable that there is a disconnect between what libraries have or will provide and what is documented on their accessibility webpages. The clearest example of the disconnect came in the comparative paucity of information about internal and external spaces, as all libraries have restrooms, lighting features, and furniture, and most likely have dedicated quiet spaces and elevators. Some of this information may not have ever been documented, but other components likely have already been compiled and documented but simply not included in this page. For example, while none of the websites reviewed by Vaughan and Warlick included information or links to library floor plans, ${ }^{39}$ and fewer than $10 \%$ of the accessibility webpages in this study did, when Wilkinson searched library websites more broadly they found the vast majority included floorplans-usually within a page containing broad "About" style information about the library or a page specific to spaces. ${ }^{40}$

Despite the disappointing aggregate results, it is worth noting that some libraries have clearly invested considerable time and effort into these pages, and even more sparse webpages sometimes provided information about interesting offering or services. There were 15 sites that the authors flagged as potential exemplars, typically either due to an overall feeling of comprehensiveness or notably strong content in a particular area, such as descriptions of physical spaces. These are listed in appendix $C$ with notes highlighting some of their particular areas of strength. Interestingly, several of the potential exemplars were Canadian institutions; these were excluded from both the study from Cassner et al. and the one from Graves and German, which focused on only US academic ARL members' websites. ${ }^{41}$ Some 
accessibility webpages also made it clear that they were actively interested in getting feedback from stakeholders, with one library soliciting recommendations for loanable assistive technology; another specifying that they had regular sessions with the campus accessibility office to review the accessibility of the website, information, resources, and services; and one asking assistive technology users to consider joining their accessible testing participant pool.

Overall, improving and expanding the library's accessibility webpage is a task that all academic libraries can engage in, and regular audits of this page can help identify needed updates or expansions based on changing circumstances. In appendix D, a suggested audit guide is included, with options to indicate if each content item is represented on the page and, if not, whether it is currently documented elsewhere and can be easily added, if information would need to be compiled, or if this would represent a new offering. While certainly not definitive, this audit can also be used to help more broadly assess the current availability of resources, services, and information about facilities for users with disabilities that the library currently provides.

\section{Limitations and Further Research}

During the process of data collection, some institutions' accessibility webpages moved or changed; and, while care was taken to try to ensure that the same webpage was reviewed for all collected data, it is possible that some discrepancies could have emerged. Data collection also coincided with the beginning of many institutions going virtual due to the pandemic, which may also have impacted some pages.

While the researchers hoped to do some basic assessment of the welcoming, or exclusionary, nature of the introductory language used on the webpages by looking at word choice and term frequency, it was determined both that terms and phrases could not be meaningfully assessed outside their specific context, and that individual interviews, or focus groups, with user with disabilities would be a much more appropriate way to assess this content. Also, initially data regarding Search Engine Optimization (SEO) for these pages was collected to look at findability of these page outside the library homepage, but ultimately the approach taken was determined to be insufficiently rigorous.

In terms of other future research, it would be very beneficial to get feedback from not only more potential users of accessibility pages, but also those who have independently navigated to these pages to learn more about what brought them to the page and what is useful or missing based on their particular point of need. Research that provides a larger picture of users' interactions with the library, such as the Photovoice method used in Eamon Tewell's (2019) study on the experiences of marginalized students, ${ }^{42}$ could also provide useful context to inform accessibility webpages and library staff's training and approach to working with users with disabilities. It is worth noting that in Brunskill's previous interview study no participants identified themselves as blind/low vision or deaf/hard of hearing. As such, specific inclusion of participants who identify as blind/low vision and deaf/hard of hearing could be very beneficial.

\section{Conclusion}

Accessibility webpages can allow users to better understand a space they have not yet explored, to learn about services they might not otherwise have known to exist, and can empower them to pursue additional needed assistance. Unfortunately, a bird's-eye view of all the ARL pages 
shows the extent of information that is still commonly omitted from these pages, with most accessibility pages not covering expected and needed information about the library's facilities, resources, and services. Clarity around what is available to students with disabilities is critical, especially since users may otherwise be uncomfortable asking and library staff may not even know the answer. An accessibility webpage provides the opportunity to connect users with disabilities with the library and its resources and to support library staff assisting these users, so greater attention to promoting and expanding these pages could pay considerable dividends. The authors hope libraries will be inspired to use their accessibility webpages as a way to better document and market information about what is available to their users with disabilities and also to identify current gaps in services, facilities, and resources that can be rectified.

\section{Acknowledgments}

Many thanks to Allan Berry, who assisted with much of the initial work for this study; to Rosie Hanneke and Tina Griffin, whose insights notably improved the manuscript; to the University of Illinois Chicago's Assistive Technology Unit for their assistance with questions about assistive technologies; and to Peter Berg at Great Lakes ADA for providing useful clarifications around the Americans with Disabilities Act and the Rehabilitation Act. 


\section{APPENDIX A. Assistive Software Listed on Webpages}

\begin{tabular}{|l|c|l|}
\hline Software & $\begin{array}{l}\text { \# Pages } \\
\text { Mentioning }\end{array}$ & Type of Software \\
\hline JAWS & $60(56 \%)$ & Screen reader \\
\hline Zoom Text & $53(50 \%)$ & Magnification \\
\hline Kurzweil & $47(44 \%)$ & Can vary based on product, not always specified \\
\hline Dragon & $35(33 \%)$ & Voice recognition \\
\hline Read \& Write & $15(14 \%)$ & Literacy software, focus on text to speech \\
\hline Open Book & $10(9 \%)$ & Text to speech, convert to large print \\
\hline FS Reader & $8(7 \%)$ & Free with JAWS \\
\hline Magic & $8(7 \%)$ & Magnification \\
\hline Inspiration & $6(6 \%)$ & For visual mapping, outlining, writing, and making \\
& & presentations \\
\hline Natural Reader & $6(6 \%)$ & Text to speech \\
\hline NVDA (NonVisual Desktop Access) & $5(5 \%)$ & Screen reader \\
\hline SensusAccess & $5(5 \%)$ & Format conversion \\
\hline ABBY Fine Reader & $4(4 \%)$ & OCR tool \\
\hline Duxbury & $5(5 \%)$ & Braille translation \\
\hline VoiceOver & $3(3 \%)$ & Screen reader \\
\hline Narrator & $3(3 \%)$ & Screen reader \\
\hline
\end{tabular}




\section{APPENDIX B. Additional Equipment/Hardware Mentioned on Webpages}

- Adaptive peripherals

- Adjustable lighting

- Antiglare lamps

- BOOX Concussion monitor/tablet

- Braille printer

- C-Pen Readerpen

- High-power Ledu reading lamp

- JAWS dongles

- Livescribe EchoPen

- LOC talking books cassette player

- Logitech Touchpad

- MAGic dongle

- Panasonic Talking Calculator

- PEARL Portable Reading Camera

- Perkins Braille typewriter

- Perkins Brailler

- Phonic Ear Easy Listener

- Pocketalker Pro personal amplification devices

- Printing House for the Blind tape recorder

- Proximity readers

- Shopping carts

- Simeon Soundfield portable voice amplifier

- Smart pens

- Speakers

- Tape and digital audio recorders

- Task lighting

- Whiteboards

- Wheelchairs 


\section{APPENDIX C. List of Potential Exemplars}

\begin{tabular}{|c|c|c|}
\hline University & URL for Accessibility Page & Notes \\
\hline $\begin{array}{l}\text { Arizona State } \\
\text { University }\end{array}$ & https://lib.asu.edu/disability & $\begin{array}{l}\text { Notably strong content in: Assistive } \\
\text { technology and equipment, as well as } \\
\text { information by location }\end{array}$ \\
\hline Florida State University & https://www.lib.fsu.edu/accessibility & Overall feel of being comprehensive \\
\hline lowa State University & $\begin{array}{l}\text { https://www.lib.iastate.edu/help- } \\
\text { services/accessibility-services }\end{array}$ & $\begin{array}{l}\text { Notably strong content in: Collections } \\
\text { and furniture descriptions }\end{array}$ \\
\hline $\begin{array}{l}\text { McGill University } \\
\text { Library }\end{array}$ & $\begin{array}{l}\text { https://www.mcgill.ca/library/services/ } \\
\text { access }\end{array}$ & $\begin{array}{l}\text { Notably strong content in: } \\
\text { Information by location }\end{array}$ \\
\hline $\begin{array}{l}\text { Michigan State } \\
\text { University }\end{array}$ & $\begin{array}{l}\text { https://lib.msu.edu/general/ } \\
\text { accessibility/ }\end{array}$ & $\begin{array}{l}\text { Overall feel of being comprehensive } \\
\text { and notably strong content in: } \\
\text { Format conversion and services }\end{array}$ \\
\hline $\begin{array}{l}\text { North Carolina State } \\
\text { University }\end{array}$ & $\begin{array}{l}\text { https://www.lib.ncsu.edu/accessibility- } \\
\text { services }\end{array}$ & $\begin{array}{l}\text { Notably strong content in: Parking, } \\
\text { building access and evacuation }\end{array}$ \\
\hline Rutgers University & $\begin{array}{l}\text { https://www.libraries.rutgers.edu/ } \\
\text { accessibility }\end{array}$ & $\begin{array}{l}\text { Notably strong content in: } \\
\text { Information by location }\end{array}$ \\
\hline Syracuse University & $\begin{array}{l}\text { https://library.syr.edu/accessibility/ } \\
\text { index.php }\end{array}$ & Overall feel of being comprehensive \\
\hline University of Alabama & $\begin{array}{l}\text { https://www.lib.ua.edu/using-the- } \\
\text { library/accessibility/ }\end{array}$ & Organization of content \\
\hline $\begin{array}{l}\text { University of California } \\
\text { Irvine }\end{array}$ & https://www.lib.uci.edu/accessibility & Overall feel of being comprehensive \\
\hline University of Guelph & $\begin{array}{l}\text { https://www.lib.uoguelph.ca/using- } \\
\text { library/library-accessibility-services }\end{array}$ & $\begin{array}{l}\text { Notably strong content in: Format } \\
\text { conversion and services }\end{array}$ \\
\hline $\begin{array}{l}\text { University of Illinois } \\
\text { Urbana Champaign }\end{array}$ & $\begin{array}{l}\text { https://guides.library.illinois.edu/ } \\
\text { usersdisabilities }\end{array}$ & $\begin{array}{l}\text { Notably strong content in: Reference } \\
\text { services and contact form }\end{array}$ \\
\hline University of Manitoba & $\begin{array}{l}\text { https://libguides.lib.umanitoba.ca/ } \\
\text { accessibility }\end{array}$ & Overall feel of being comprehensive \\
\hline University of Michigan & https://www.lib.umich.edu/accessibility & $\begin{array}{l}\text { Overall feel of being comprehensive } \\
\text { and notably strong content in: } \\
\text { Detailed and actionable descriptions }\end{array}$ \\
\hline $\begin{array}{l}\text { University of North } \\
\text { Carolina Chapel Hill }\end{array}$ & $\begin{array}{l}\text { https://library.unc.edu/services/ } \\
\text { disability-services/ }\end{array}$ & $\begin{array}{l}\text { Notably strong content in: } \\
\text { Information by location }\end{array}$ \\
\hline
\end{tabular}




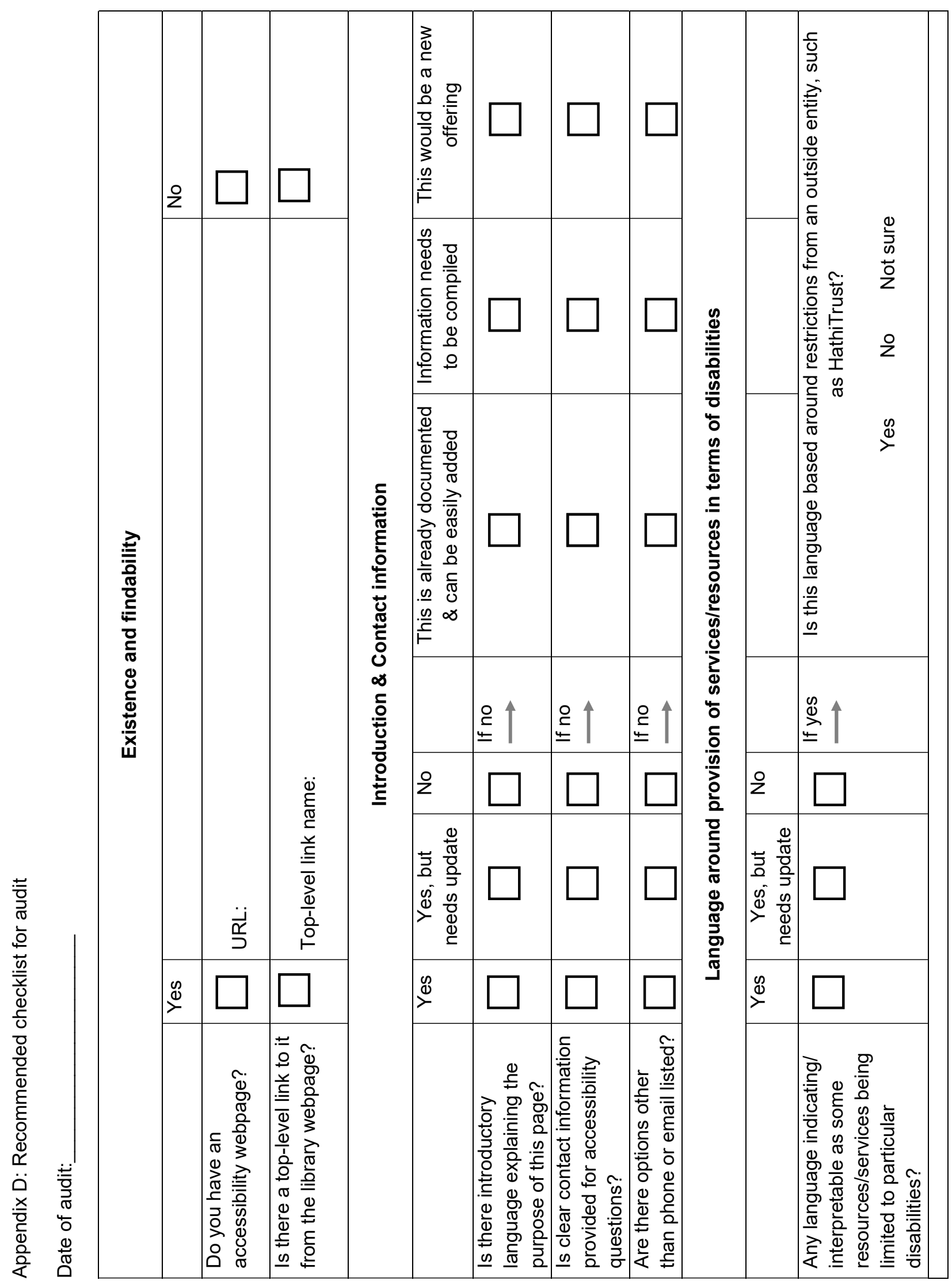




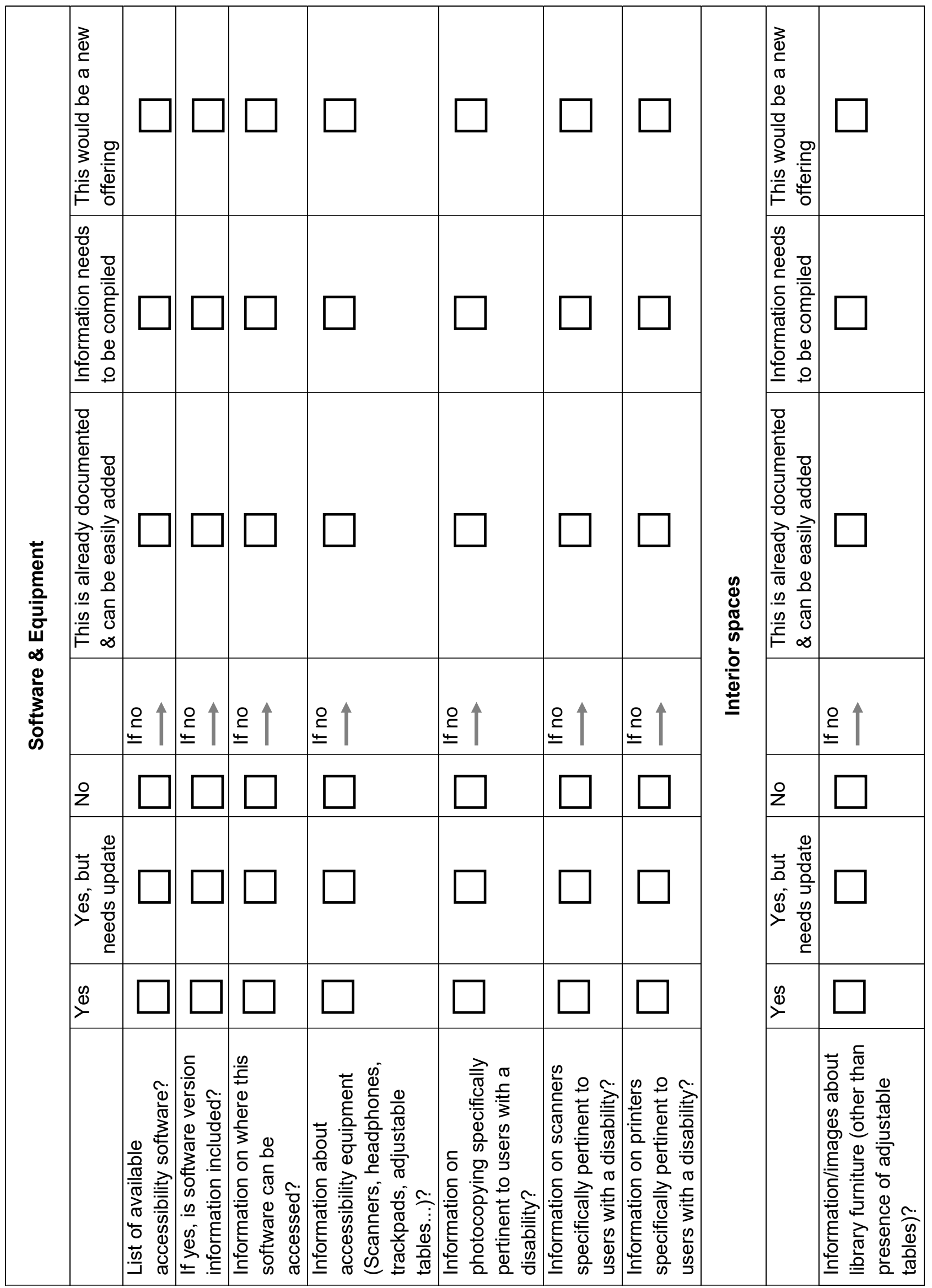




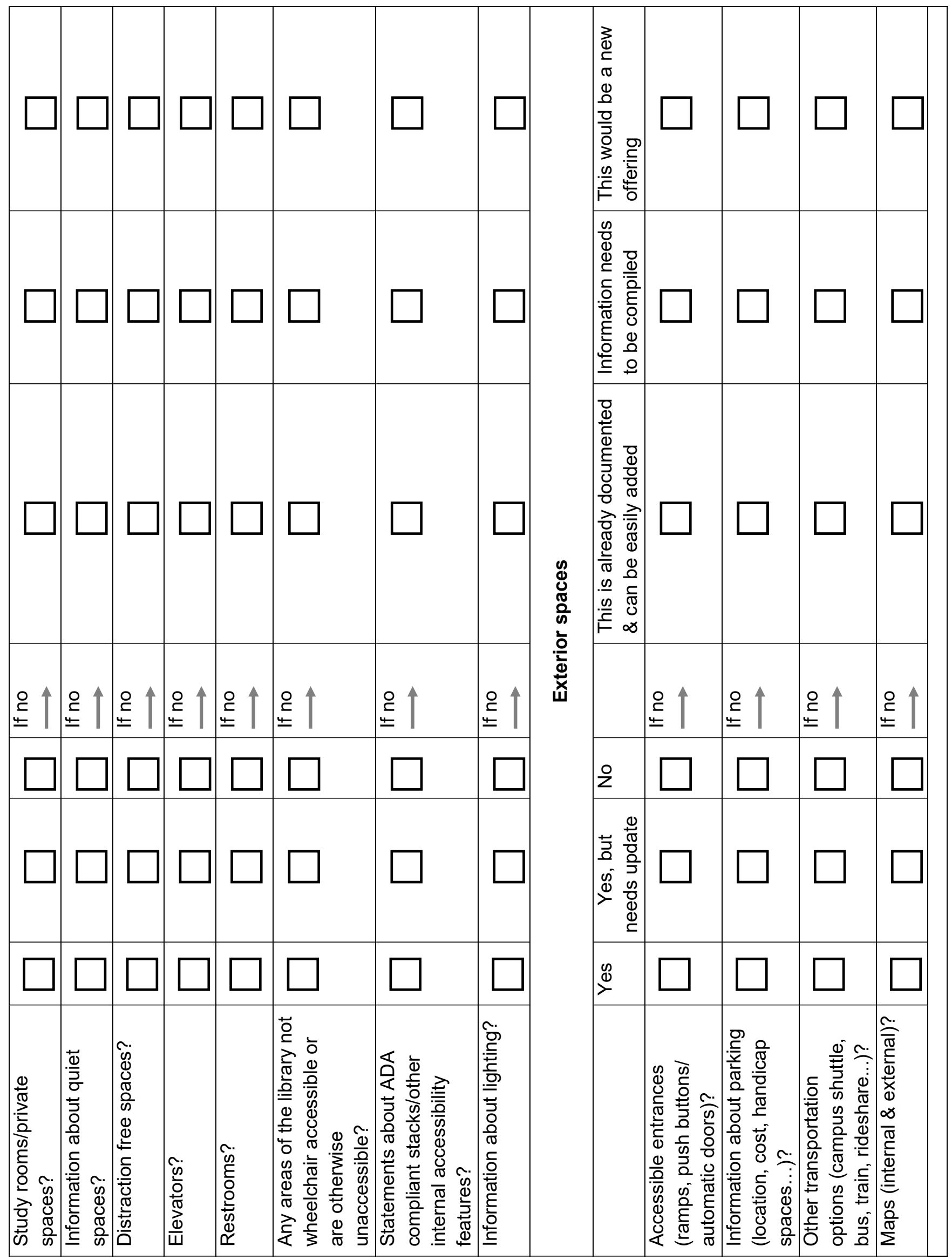




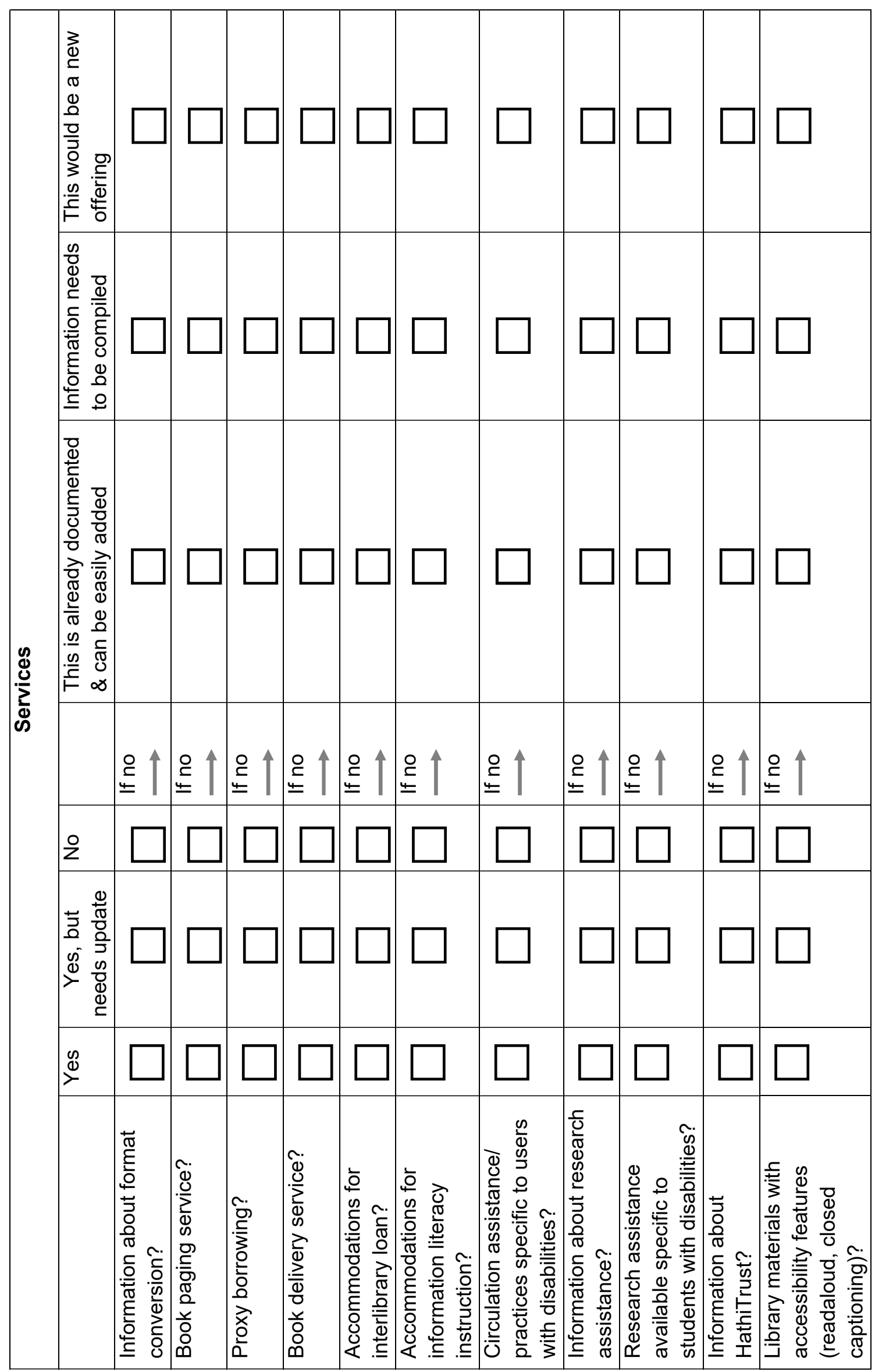




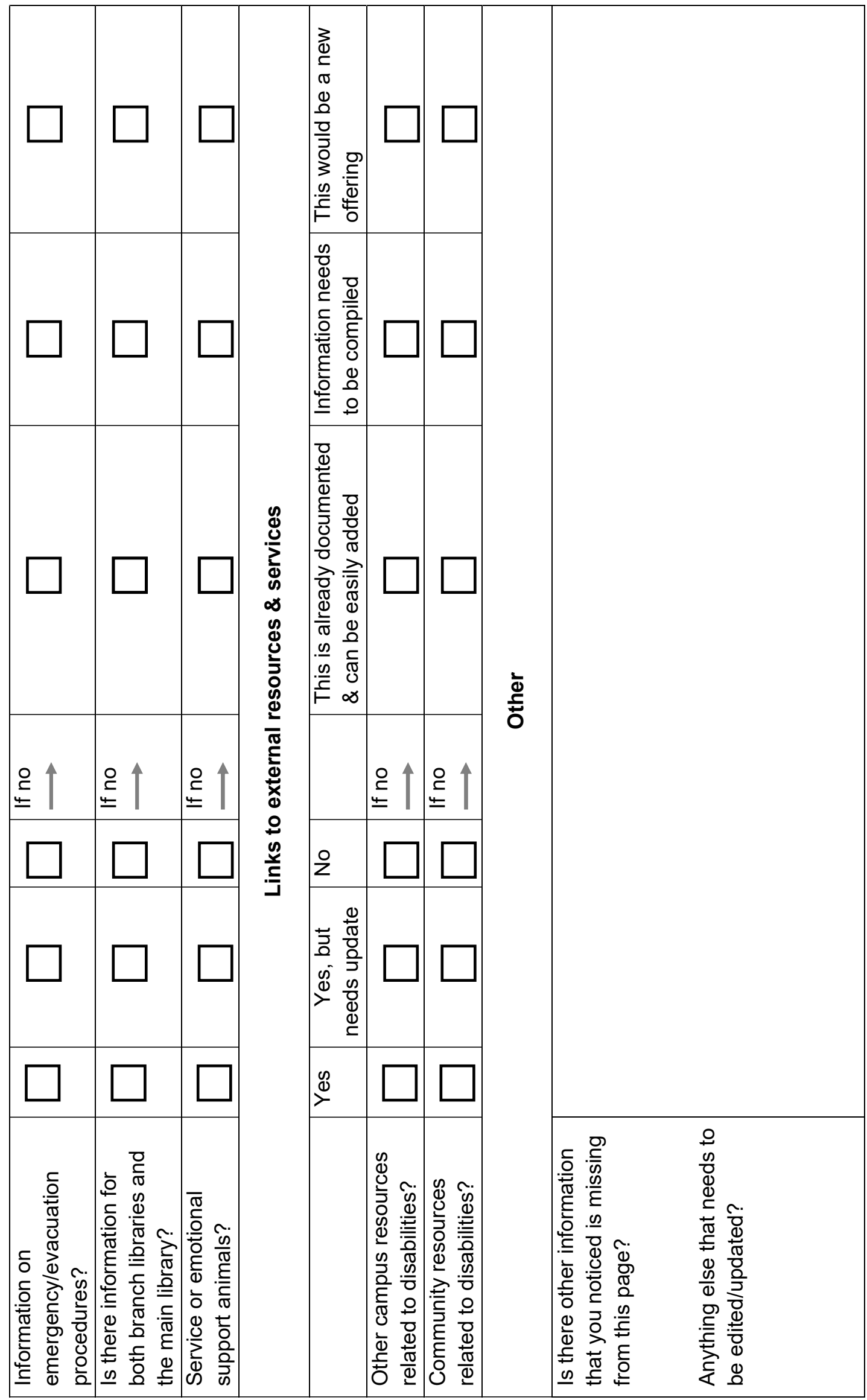




\section{Notes}

1. Carli Spina and Margaret Cohen, "Accessibility and Universal Design, SPEC Kit 358," May 2, 2018, https:// publications.arl.org/Accessibility-Universal-Design-SPEC-Kit-358/.

2. Stephanie J. Graves and Elizabeth German, "Evidence of Our Values: Disability Inclusion on Library Instruction Websites," portal: Libraries and the Academy 18, no. 3 (2018): 559-74; Mary Cassner, Charlene MaxeyHarris, and Toni Anaya, "Differently Able: A Review of Academic Library Websites for People with Disabilities," Behavioral and Social Sciences Librarian 30, no. 1 (2011): 33-51, https://doi.org/10.1080/01639269.2011.548722.

3. Cassner, Maxey-Harris, and Anaya, "Differently Able"; Graves and German, "Evidence of Our Values"; Rebecca Power and Chris LeBeau, "How Well Do Academic Library Web Sites Address the Needs of Database Users with Visual Disabilities?" Reference Librarian 50, no. 1 (2009): 55-72; K.T.L. Vaughan and Stefanie E. Warlick, "Accessibility and Disability Services in Virginia's Four-Year Academic Libraries: A Content Analysis of Library Webpages," Virginia Libraries 64, no. 1 (June 2, 2020): 2, https://doi.org/10.21061/valib.v64i1.600.

4. Amelia Brunskill, “'Without That Detail, I'm Not Coming': The Perspectives of Students with Disabilities on Accessibility Information Provided on Academic Library Websites," College and Research Libraries 81, no. 5 (2020): 768, https://doi.org/10.5860/crl.81.5.768.

5. Serena E. Hinz, Caren A. Arbeit, and Alexander Bentz, "Characteristics and Outcomes of Undergraduates with Disabilities: Web Tables" (December 2017), https://nces.ed.gov/pubs2018/2018432.pdf; Ahmed K. Ibrahim et al., "A Systematic Review of Studies of Depression Prevalence in University Students," Journal of Psychiatric Research 47, no. 3 (March 1, 2013): 391-400, https://doi.org/10.1016/j.jpsychires.2012.11.015; Consuelo M. Kreider, Roxanna M. Bendixen, and Barbara J. Lutz, "Holistic Needs of University Students with Invisible Disabilities: A Qualitative Study," Physical and Occupational Therapy in Pediatrics 35, no. 4 (November 2015): 426-41, https:// doi.org/10.3109/01942638.2015.1020407.

6. American with Disabilities Act of 1990, 42 U.S.C. ch.126 § 12101 et seq.

7. Rehabilitation Act of 1973, 29 U.S.C. § 701 et seq.

8. W3C, "Web Content Accessibility Guidelines (WCAG) Overview" (2018),

https://www.w3.org/WAI/standards-guidelines/wcag/.

9. Lucy Barnar-Brak, DeAnn Lectenberger, and William Y. Lan, "Accommodation Strategies of College Students with Disabilities," Qualitative Report 15, no. 2 (2010): 411-29; Laura Mullins and Michèle Preyde, "The Lived Experience of Students with an Invisible Disability at a Canadian University," Disability and Society 28, no. 2 (2013): 147-60.

10. Laura Marshak et al., "Exploring Barriers to College Student Use of Disability Services and Accommodations," Journal of Postsecondary Education and Disability 22, no. 3 (2010): 151-65; Kirsten L Lightner et al., "Reasons University Students with a Learning Disability Wait to Seek Disability Services," Journal of Postsecondary Education and Disability 25, no. 2 (2012): 145-59.

11. Nahid Bayat Bodaghi, Loh Sau Cheong, and A.N. Zainab, “Librarians Empathy: Visually Impaired Students' Experiences Towards Inclusion and Sense of Belonging in an Academic Library," Journal of Academic Librarianship 42, no. 1 (2016): 87-96, https://doi.org/10.1016/j.acalib.2015.11.003.

12. J.J. Pionke, "Toward Holistic Accessibility: Narratives from Functionally Diverse Patrons," Reference and User Services Quarterly 57, no. 1 (2017): 48-56.

13. Sue Samson, "Best Practices for Serving Students with Disabilities," Reference Services Review 39, no. 2 (2011): 260-77.

14. Joanne Oud, "Systemic Workplace Barriers for Academic Librarians with Disabilities," College and Research Libraries 80, no. 2 (2019): 169-94.

15. J.J. Pionke, "Library Employee Views of Disability and Accessibility," Journal of Library Administration 60, no. 2 (February 2020): 120-45.

16. Spina and Cohen, "Accessibility and Universal Design, SPEC Kit 358."

17. Power and LeBeau, "How Well Do Academic Library Web Sites Address the Needs of Database Users with Visual Disabilities?"

18. Cassner, Maxey-Harris, and Anaya, "Differently Able."

19. Graves and German, "Evidence of Our Values."

20. Vaughan and Warlick, "Accessibility and Disability Services in Virginia's Four-Year Academic Libraries."

21. Vaughan and Warlick, "Accessibility and Disability Services in Virginia's Four-Year Academic Libraries."

22. Gerard Shea and Sebastian Derry, "Academic Libraries and Autism Spectrum Disorder: What Do We Know?" Journal of Academic Librarianship 45, no. 4 (July 1, 2019): 326-31, https://doi.org/10.1016/j.acalib.2019.04.007; Pionke, "Toward Holistic Accessibility."

23. Clayton A. Copeland, "Library and Information Center Accessibility: The Differently-Able Patron's Per- 
spective," Technical Services Quarterly 28, no. 2 (2011): 223-41, https://doi.org/10.1080/07317131.2011.546281.

24. Pionke, "Toward Holistic Accessibility."

25. Wondwossen M. Beyene, "Digital Inclusion in Library Context: A Perspective from Users with Print Disability," Journal of Web Librarianship 12, no. 2 (2018): 121-40.

26. Adina Mulliken, "Eighteen Blind Library Users' Experiences with Library Websites and Search Tools in US Academic Libraries: A Qualitative Study," College and Research Libraries 80, no. 2 (2018): 152-68; Bodaghi, Cheong, and Zainab, "Librarians Empathy"; Nihal Menzi-Cetin et al., "Evaluation of a University Website's Usability for Visually Impaired Students," Universal Access in the Information Society 16, no. 1 (2017): 151-60; Power and LeBeau, "How Well Do Academic Library Web Sites Address the Needs of Database Users with Visual Disabilities?"; Wondwossen Mulualem Beyene, "Resource Discovery and Universal Access: Understanding Enablers and Barriers from the User Perspective," in Studies in Health Technology and Informatics, 2016/08/19 ed., Studies in Health Technology and Informatics 229 (IOP Press, 2016), 556-66; Beyene, "Digital Inclusion in Library Context."

27. Joanne Oud, "How Well Do Ontario Library Web Sites Meet New Accessibility Requirements?" Partnership: The Canadian Journal of Library and Information Practice and Research 7, no. 1 (2012); Wenfan Yang et al., "Are Ivy League Library Website Homepages Accessible?" Information Technology and Libraries 39, no. 2 (2020): 1-18; Arif Khan, Haroon Idrees, and Khan Mudassir, "Library Web Sites for People with Disability: Accessibility Evaluation of Library Websites in Pakistan," Library Hi Tech News 32, no. 6 (2015): 1-7, https://doi.org/10.1108/LHTN-01-20150010; Erica B. Lilly and Connie Jean Van Fleet, "Wired but Not Connected: Accessibility of Academic Library Home Pages," Reference Librarian, no. 67-68 (1999): 5-28; Lisa Billingham, "Improving Academic Library Website Accessibility for People with Disabilities," Library Management 35, no. 8 (2014): 565-81, https://doi.org/10.1108/LM11-2013-0107; Daniel Earl Wilson, "Web Content and Design Trends of Alabama Academic Libraries," Electronic Library 33, no. 1 (February 2015): 88-102, https://doi.org/10.1108/EL-05-2013-0100; Elizabeth Leonard, “Dream the Impossible Dream: A Case Study of U.S. Federal Website Accessibility Standards Compliance at Seton Hall University Libraries," International Information and Library Review 50, no. 1 (2018): 34-39, https://doi.org/10.1080/10 572317.2018.1422908; Isabel Mariann Silvis, Theo J.D. Bothma, and Koos J.W. de Beer, “Evaluating the Usability of the Information Architecture of Academic Library Websites," Library Hi Tech 37, no. 3 (July 2019): 566-90, https:// doi.org/10.1108/LHT-07-2017-0151; Dave Comeaux and Axel Schmetzke, "Accessibility of Academic Library Web Sites in North America: Current Status and Trends (2002-2012)," Library Hi Tech 31, no. 1 (February 2013): 8-33, https://doi.org/10.1108/07378831311303903; Ankur Pant, "Usability Evaluation of an Academic Library Website," Electronic Library 33, no. 5 (2015): 896-915, https://doi.org/10.1108/EL-04-2014-0067.

28. Brunskill, "'Without That Detail, I'm Not Coming."'

29. Anna Mierzecka and Andrius Suminas, "Academic Library Website Functions in the Context of Users' Information Needs," Journal of Librarianship and Information Science 50, no. 2 (June 1, 2018): 157-67, https://doi. org/10.1177/0961000616664401.

30. Rachel M. McMullin and Kerry R. Walton, "Sensory Issues, Physical Environment, and Library Spaces," in Supporting Students on the Autism Spectrum: A Practical Guide for Academic Libraries (Santa Barbara, CA: ABCCLIO, 2019), 15-28.

31. Jaci Wilkinson and Kyle Breneman, "Bridging the Digital and the Physical User Experience: Analysis of Academic Library Floor Plans," Journal of Web Librarianship 14, no. 1/2 (April 2, 2020): 28-51, https://doi.org/10.10 80/19322909.2020.1788497.

32. "List of ARL Members," Association of Research Libraries, accessed January 29, 2021, https://www.arl.org/ list-of-arl-members/.

33. Kyunghye Yoon, Laura Hulscher, and Rachel Dols, "Accessibility and Diversity in Library and Information Science: Inclusive Information Architecture for Library Websites," Library Quarterly 86, no. 2 (March 17, 2016): 213-29, https://doi.org/10.1086/685399.

34. Cassner, Maxey-Harris, and Anaya, "Differently Able."

35. Cassner, Maxey-Harris, and Anaya, "Differently Able."

36. Brunskill, "'Without That Detail, I'm Not Coming."”

37. Vaughan and Warlick, "Accessibility and Disability Services in Virginia's Four-Year Academic Libraries." 38. Spina and Cohen, "Accessibility and Universal Design, SPEC Kit 358."

39. Vaughan and Warlick, "Accessibility and Disability Services in Virginia's Four-Year Academic Libraries." 40. Wilkinson and Breneman, "Bridging the Digital and the Physical User Experience."

41. Cassner, Maxey-Harris, and Anaya, "Differently Able."

42. Eamon Tewell, "Reframing Reference for Marginalized Students: A Participatory Visual Study," Reference and User Services Quarterly 58, no. 3 (Spring 2019): 162-76, https://doi.org/10.5860/rusq.58.3.7044. 